\title{
Religious Coping as Mediator between Illness Perception and Health-Related Quality of Life among Chronic Kidney Disease Patients
}

\author{
Norhayati Ibrahim ${ }^{1}$, Asmawati Desa ${ }^{2} \&$ Norella Kong Chiew-Tong ${ }^{3}$ \\ ${ }^{1}$ Health Psychology Unit, Faculty of Allied Health Sciences, Universiti Kebangsaan Malaysia, Jalan Raja Muda \\ A. Aziz, Malaysia \\ ${ }^{2}$ School of Psychology and Human Development, Faculty of Social Sciences and Humanities, Universiti \\ Kebangsaan Malaysia, Bangi, Malaysia \\ ${ }^{3}$ Nephrology/Dialysis and SLE Unit, UKM Medical Centre, Faculty of Medicine, Jalan Yaacob Latif, Bandar \\ Tun Razak, Cheras, Malaysia \\ Correspondence: Norhayati Ibrahim, Health Psychology Unit, Faculty of Allied Health Sciences, Universiti \\ Kebangsaan Malaysia, 43600 UKM Bangi, Selangor, Malaysia. Tel: 60-12-275-7475. E-mail: \\ norhayati70@gmail.com
}

Received: June 4, 2012 Accepted: June 16, $2012 \quad$ Published: July 16, 2012

doi:10.5539/ass.v8n9p23 URL: http://dx.doi.org/10.5539/ass.v8n9p23

\begin{abstract}
End-stage renal disease (ESRD) a raising global pandemic known to cause psychological dysfunction but not well studied. The purpose of this study was to measure the influence of illness perception and religious coping strategies on patients' health-related quality of life (HRQoL) and to identify direct or indirect predictors of religious coping on illness perception and HRQoL of ESRD patients. This study involved 274 patients with ESRD who were on chronic maintenance dialysis. Test instruments used included Revised Illness Perception Questionnaire (IPQ-R) to measure patients' perception towards the illness, Religious Coping Strategies questionnaire (RCS) to determine patients' nature of religious coping and Short-Form 36 (SF-36) questionnaire to measure their HRQoL. Results showed that almost all components of illness perception and religious coping strategies were significantly correlated with HRQoL in both aspects of physical component summary (PCS) and mental component summary (MCS). In addition, the findings showed religious coping as a mediator between several illness perception components namely timeline, illness coherence, personal control, consequences and cyclical with PCS and MCS. Attention should be given especially to illness perception and positive religious coping variables in any intervention program to improve the HRQoL of ESRD patients.
\end{abstract}

Keywords: health related quality of life, end-stage renal disease, religious coping, illness perception

\section{Introduction}

There are more Malaysians suffering from the end-stage renal disease than ever before. Statistics from the Malaysian National Renal Registry (2009) showed that the number of new dialysis patients had continued to increase linearly over the past decade - from 1,136 patients in 1997 to at least 4,146 patients in 2009. At the end of 2009, a total of 21,159 patients were reported to rely on dialysis, giving a prevalence rate of 550 per million of population (Malaysian National Renal Registry 2009).

Despite the increase in the number of dialysis patients and dialysis centers provided by the Malaysian Ministry of Health, NGOs and private centers, virtually nothing is known about the psychological states of the patients receiving the various treatments, especially with regards to their emotional well-being and psycho-social functioning. Health-related quality of life (HRQoL) of ESRD patients has always drawn the attention of previous researchers in an attempt to understand how they cope with such a chronic illness. Interest in quality of life research can be attributed to a number of factors. Firstly, there is an increasing epidemic of chronic disease today. Secondly, ESRD has a major impact on patients' HRQoL, affecting their physical and mental health, functional 
status, independence, general well-being, interpersonal relationships and social functioning. Thirdly, HRQoL in ESRD patients has been shown to be a significant predictor of mortality and hospitalization (Mapes et al., 2003).

Their perception of ESRD and the need for dialysis play an important role in influencing the patients' quality of life. Recent study by Norhayati et al. (2011b) towards HD patients demonstrated that illness perception plays a significant role in HRQoL. Three components of illness perception (consequences, identity and illness coherence) and five components of illness perception (emotional, consequences, identity, treatment control and illness coherence) became a good predictor to PCS and MCS aspects of HRQoL. According to Reynolds and Alonzo (2000), illness perception acts as an adaptation and self-control process which depends on the evaluation of the perception towards behavior. Whereas according to Cameron and Moss-Morris (2004), illness perception can be stated as the patient's reaction in processing, accepting and demonstrating a response to the stimulation experienced, rooted from the pain and suffering caused by the health complications. It involves a set of planned beliefs and it reflects the way in which the disease can affect the body, one's life activities and depends on whether it can be cured or not.

Illness perception is an important concept since the patients' beliefs provide guidance to the patients to react towards the symptoms, the diagnosis and other information associated with the disease. However, every human being is different not only from the accuracy of the perception of disease but also regarding its treatment and associated medications. Some patients may understand their disease clearly whilst others may not (Moss-Morris et al., 2002). According to Cameron and Moss-Morris (2004), the individual's exposure to various social and cultural information sources will influence how he or she perceives the disease. For example, information gained from the latest stories and anecdotes, learning at school, personal experience related to the disease or experience by family members and friends, books, television or other media will contribute to the moulding of illness perception. ESRD and its treatment will lead to myriad of physical and psychosocial pressures that will pose a challenge to the patients.

Patients diagnosed with ESRD have to undergo treatment and have used various strategies to adapt themselves to the stresses and stressors that they have to face. The coping strategies adopted by the patients depend on their personal experiences, the social support system, individual beliefs and the availability of resources (Mok and Tam, 2001; Tsay et al., 2005). The process of coping involves cognitive appraisal of a threat followed by attempts to either remove or mitigate the effects of treatment. Patel et al. (2002) suggested that religious involvement and stronger perception of the importance of faith are associated with less depression. A preliminary study by Finkelstein et al. (2007) found that there was a strong correlation between spirituality and several domains of quality of life such as mental and global assessment of the patients' quality of life. According to the Common-Sense Model, religious coping strategies can act as mediator in the relationship between illness perception and the outcome of assessment (e.g, health-related life quality) (Heijmans, 1998; Helder et al., 2002). Religious coping strategies refer to the employment of the cognitive and behavioural techniques when faced with stressful situations, in individuals with religious principles (Tix and Frazier, 1998). In other words, through religious coping strategies, humans attempt to comprehend these stressful situations via their religious belief systems (Gall and Grant, 2005).

Recently, there has been great concern about the role of spiritual aspects in health care (Kimmel et al., 2003; Mattison, 2006; Finkelstein et al., 2007; Ko et al., 2007). The importance of religious coping in helping patients with this challenging disease should be given proper attention especially in the Malaysian context because there is scarce research on this variable to date. This cohort study emphasizes on the religious coping strategies used by ESRD patients on chronic dialysis and their influence on illness perception and HRQoL.

\section{Method}

\subsection{Sample}

This study involved 274 patients with ESRD who were undergoing either haemodialisis (HD) or continuous ambulatory peritoneal dialysis (CAPD) at outpatient facilities affiliated with the Universiti Kebangsaan Malaysia Hospital (HUKM). Dialysis patients at MAA- Medicare Kidney Charity Fund Dialysis Centre at Jalan Ipoh, Kajang and Cheras and those under the care of the Batu Pahat Johor Medical Centre were also recruited

\subsection{Instruments}

Short Form - 36 (SF-36): Quality of life was assessed using the Short Form-36 (SF-36) which evaluates various aspects of functioning and well-being in order to provide an overall impression of HRQoL. This form is developed as the best compromise between response and burdens. It is a generic self-completed questionnaire 
with eight dimensions that include physical functioning, physical role limitation, emotional role limitation, social functioning, pain, mental health, vitality and general health perception. These contribute to the evaluation of two major aspects of patients' functioning - the physical component summary (PCS) and mental component summary (MCS) (Ware et al., 1993). It takes approximately 15 minutes to answer the questions. Scoring is by summing the responses for each of the items in the dimensions and converting them into a scoring algorithm, to a scale from 0 (poor health) to 100 (good health). A higher score indicates better functioning, less pain or greater well-being.

Revised Illness Perception Questionnaire (IPQ-R): The illness perception was assessed with a well-validated Revised Illness Perception Questionnaire developed by Moss-Morris et al. (2002). The IPQ-R assesses nine components of illness representation in three sections. The first section includes the subscale identity - in which participants were asked yes/no questions for 18 different symptoms and whether they believed these symptoms related to them. The second section consists of 38 questions which address seven subscales - time-line, cyclical (nature), consequences, personal control, treatment control, coherence and emotional response. The patients rate the items on a five-point scale, ranging from $1=$ 'strongly disagree' to $5=$ 'strongly agree'. The time-line dimension is assessed by six items. A higher score in this dimension indicates the patient's perception of the chronic course of the disease. Cyclical is assessed by four items, whereby patients view their illness as episodes that come and go over time. The consequence dimension is assessed by six items and a higher score indicates that the patient considers the disease as having serious consequences upon his/her life. Personal control dimension assessment comprises five items and a higher score indicates the perception of better personal control of the disease.

Treatment control is assessed by five items and a higher score indicates that the patient considers dialysis to be efficient in controlling ESRD. Coherence is a measure of how well the patient understands his or her illness. It is evaluated by five items - a higher score indicates the patient has an increased understanding of their disease and treatment. The last dimension assesses emotional response which involves six items. A higher score in this dimension indicates more intense emotional reaction to the disease. The final section focuses on the subscale causes. This scale consists of 18 possible causes for being on dialysis (e.g., lifestyle, hereditary factors, chance, behavior, uncertainty). This scale also uses the five-point Likert scale.

Religious Coping Strategies: This instrument has been constructed by the researchers. It contains 20 items that examine 2 sub-scales of religious coping strategies in both positive and negative forms. The development of the test equipment is based on Pargament's religious coping scale with modification which was deemed appropriate to the religion and culture in Malaysia. After factor analysis was conducted, the reliability of the instrument was found to be at $\alpha=0.88$ (Norhayati et al., 2011a).

\subsection{Procedures}

Upon approval from the Universiti Kebangsaan Malaysia, Scientific Research and Ethical Committe, subjects who met the criteria and gave informed consent were interviewed individually by the researcher. HD patients were interviewed when they were undergoing their four-hour treatment. CAPD patients were interviewed whilst they were waiting in the clinic for review by their doctors/nurse trainees. Patients were assessed using the Short-form 36 (SF-36), Illness Perception Questionnaire-Revised (IPQ-R) and Religious Coping Strategies (RCS).

\subsection{Data Analysis}

Data were analyzed using the Statistical Package for Social Sciences (SPSS) version 18.0. Descriptive statistics were used to describe the patient's background. Pearson correlation analysis and multiple regressions with enter method were also used in this study.

\section{Results}

Table 1 shows the demographic profile of the study. Of the 274 patients, $51.5 \%$ were males and $48.5 \%$ females. Majority was Malays (49.3\%), married (75.9\%), Muslims (52.2\%) and age ranged 51 to 60 years (37.6\%). Most of the patients were unemployed (74.2\%) and only a small percentage of the unemployed patients received their monthly pension (18.2\%). The remaining $25.6 \%$ of participants were still working. Most of the patients $66.8 \%$ were on HD treatment and the remaining $33.2 \%$ on CAPD treatment. Approximately half of the patients $50.7 \%$ were on dialysis for less than 36 months, whereas $36.6 \%$ had been on treatment for 36-120 months and the remaining $12.8 \%$ for more than 120 months. (refer Table 1 ). 
Table 1. Demographic profile of the study population

\begin{tabular}{lll}
\hline Variable & Frequency & Percentage (\%) \\
\hline Gender & 141 & 51.5 \\
Male & 133 & 48.5 \\
Female & & \\
Ethnicity & 135 & 49.3 \\
Malay & 110 & 40.1 \\
Chinese & 23 & 8.4 \\
Indian & 6 & 2.2 \\
Others & & \\
Religion & 143 & 52.2 \\
Islam & 80 & 29.2 \\
Buddhism & 22 & 8.0 \\
Hinduism & 11 & 4.0 \\
Christianity & 18 & 6.6 \\
Others & & \\
Age & 50 & 18.2 \\
$<40$ years & 53 & 19.3 \\
$40-50$ years & 103 & 37.6 \\
$51-60$ years & 68 & 24.8 \\
$>60$ years & & \\
Marital status & 34 & 12.4 \\
Married & 208 & 75.9 \\
Single & 32 & 11.7 \\
Divorced/Widowed & & \\
Working status & 70 & 25.6 \\
Employment & 154 & 56.2 \\
Unemployment without pension & 50 & 18.2 \\
Unemployment with pension & & \\
Type of dialysis & 183 & 66.8 \\
HD & 91 & 33.2 \\
CAPD & 139 & 50.7 \\
Length of treatment & 100 & 36.5 \\
$<36$ months & 35 & 12.8 \\
36 - 120 months & & \\
$>120$ months & & \\
\hline Table & & \\
\hline
\end{tabular}

Table 2 shows the relationship between illness perception, religious coping and PCS and MCS using Pearson's correlation. Patients with good personal control perceived their illness as less chronic, had greater faith in treatment and had a greater understanding of their illness and its treatment. Patients who perceived their illness as chronic also perceived more consequences of the illness on their lives and reported more symptoms. Those who reported their illness as occurring in a cyclical nature perceived more consequences, demonstrated less understanding about ESRD, perceived more symptoms and causes of their illness. Treatment control had a positive relationship with illness coherence, where patients who had greater faith in their treatment had a greater understanding of their illness. Those who perceived greater impact of the illness on their lives, reported less understanding about the illness, were emotionally less stable and experienced more symptoms and causes from the illness. Those who had higher illness coherence also reported less emotional instability and perceived fewer causes to the illness. Patients who had positive religious coping had perceived their illness to be less chronic, of a cyclical nature, had good personal control, experienced fewer consequences and better understanding of the illness. Almost all of the illness perception components except for treatment control and religious coping were associated with the PCS. In addition, all illness perception components and religious coping correlated with the MCS. (see Table 2). 
Table 2. Relationship between components of the illness perception, religious coping and health-related quality of life

\begin{tabular}{|c|c|c|c|c|c|c|c|c|c|c|c|}
\hline & (1) & (2) & (3) & (4) & (5) & (6) & (7) & (8) & (9) & (10) & (11) \\
\hline (1) Time line & - & - & - & - & - & - & - & - & - & - & - \\
\hline (2) Cyclical & -0.05 & - & - & - & - & - & - & - & - & - & - \\
\hline (3) Personal control & $-0.17^{*}$ & -0.08 & - & - & - & - & - & - & - & - & - \\
\hline $\begin{array}{l}\text { (4) Treatment } \\
\text { control }\end{array}$ & 0.06 & 0.04 & $0.14 *$ & - & - & - & - & - & - & - & - \\
\hline (5) Consequences & $0.21 * *$ & $0.13^{*}$ & -0.09 & -0.11 & - & - & - & - & - & - & - \\
\hline (6) Illness coherence & -0.04 & $-0.23 * *$ & $0.22^{* *}$ & $0.14^{*}$ & $-0.29 * *$ & - & - & - & - & - & - \\
\hline (7) Emotional & -0.01 & 0.01 & -0.03 & -0.11 & $0.43^{* *}$ & $-0.40 * *$ & - & - & - & - & - \\
\hline (8) Identity & $0.16^{* *}$ & $0.28 * *$ & -0.12 & -0.10 & $0.26^{* *}$ & -0.12 & $0.28 * *$ & - & - & - & - \\
\hline (9) Causes & 0.04 & $0.24 * *$ & 0.02 & -0.11 & $0.21 * *$ & $-0.30 * *$ & $0.26^{* *}$ & $0.31 * *$ & - & - & - \\
\hline $\begin{array}{l}\text { (10) Religious } \\
\text { coping }\end{array}$ & $-0.19 * *$ & $-0.12^{*}$ & $0.40^{* *}$ & 0.02 & $-0.13^{*}$ & $0.32 * *$ & -0.06 & 0.07 & 0.09 & - & - \\
\hline (11) PCS & $-0.22 * *$ & $-0.37^{* *}$ & $0.21 * *$ & 0.09 & $-0.31 * *$ & $0.31 * *$ & $-\overline{0.29 * *}$ & $-0.41 * *$ & $-0.24 * *$ & $0.18 * *$ & - \\
\hline (12) MCS & $-0.26^{* *}$ & $-0.27^{* *}$ & $0.20^{* *}$ & $0.12^{*}$ & $-0.34 * *$ & $0.34 * *$ & $-\overline{0.34 * *}$ & $-0.35 * *$ & $-0.19 * *$ & $0.29 * *$ & $0.75 * *$ \\
\hline
\end{tabular}

** Correlation is significant at 0.01 level (2-tailed). ${ }^{*}$ Correlation is significant at 0.05 level (2-tailed).

The relationship between illness perception, religious coping and HRQoL (PCS and MCS) were analyzed using regression analysis (See Figure 1 and Figure 2). The components of illness perception explained $35 \%$ of the variance in PCS and 33\% in MCS. These components influenced PCS and MCS indirectly through religious coping. The relationship between chronic timeline, illness coherence, personal control, consequences and cyclical with PCS and MCS was mediated by religious coping. The more the patients perceive their illness as chronic; the more coherent was their perception towards the illness, with more personal control, and greater use of positive religious coping; which in turn had a positive effect on PCS and MCS. Likewise, the less their illness was perceived as having an effect on their lives and as cyclical; the fewer the positive coping strategies were resorted to. Less positive religious coping was associated with poorer PCS and MCS.

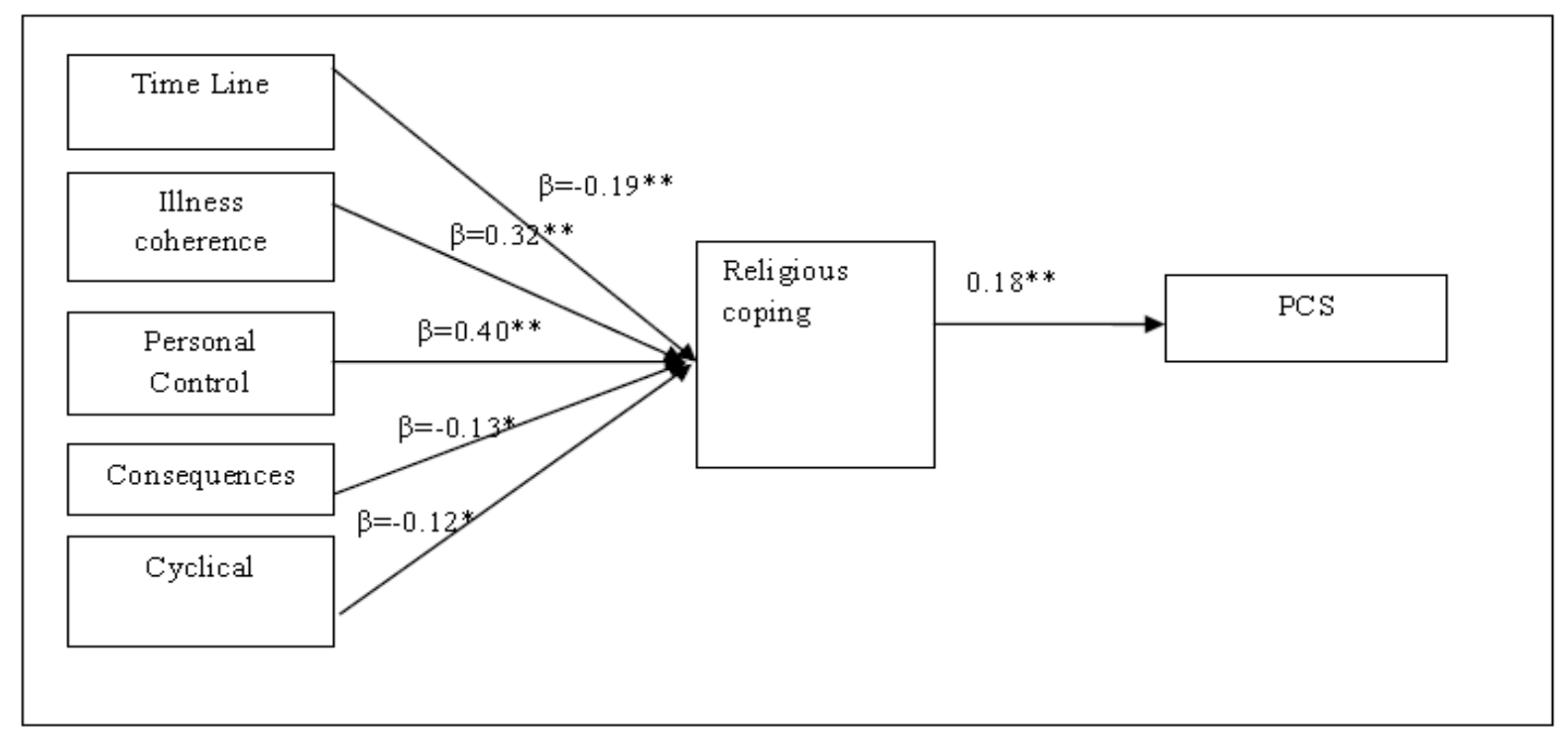

Figure 1. Results of the regression analysis for the physical component summary

Notes: ${ }^{*} \mathrm{p}<0.05,{ }^{* *} \mathrm{p}<0.01$.

PCS: $\mathrm{R}^{2}=0.35, \mathrm{~F}=15.91$ 


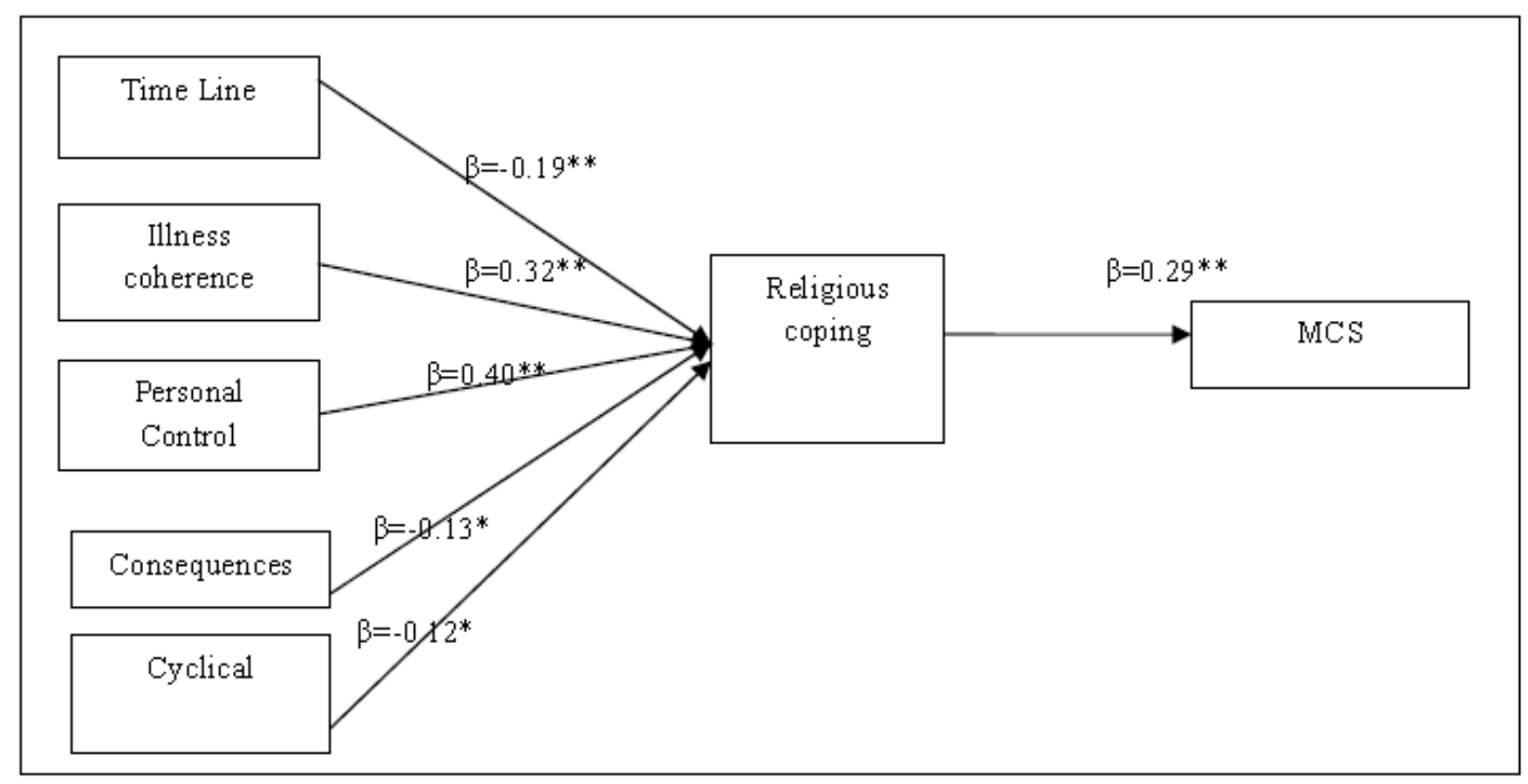

Figure 2. Results of regression analysis for the mental component summary

Notes: ${ }^{*} \mathrm{p}<0.05,{ }^{* *} \mathrm{p}<0.01$

MCS: $\mathrm{R}^{2}=0.33, \mathrm{~F}=14.56$

\section{Discussion}

This study demonstrated that majority of the illness perception components were associated with PCS and MCS. These findings support the study conducted by Timmers et al., (2008) who found that patients experienced more symptoms and lower self-control were linked to a lower degree of well-being. Whereas the study by Fowler and Baas (2006) reported that illness perception was related to the components of emotion, effect of disease and quality of life. Nonetheless, the findings of this study were consistent with the theory of illness perception or better known as the Common-Sense Model of self-regulation. This model explains how illness perception which involves time line, causes of the disease, consequences, control and identity as well as emotion can affect one's state of health. According to this model, one's perception of illness is generated from one's previous experience related to health and disease and knowledge about ways to overcome or deal with a disease.

The results of this study also showed that religious coping strategies mediated the relationship between time line, illness coherence, personal control, consequences of disease and the cycle with PCS and MCS. These findings support the Common-Sense Model which explains how illness perception is related with the various coping strategies and further influences the outcome in this case, the HRQoL. According to Hagger and Orbell (2005), the information gathered by patients and how they perceive their condition within the scope of their understanding will impact the patients' personal viewpoints on their own diseases, in turn, these views will formulate the coping behavior of the patients and will elicit either positive or negative responses.

The Common-Sense Model is said to resemble the Lazarus Transactional Theory of Stress and Coping. According to the Lazarus theory, when a situation is perceived to be stressful, the coping strategy will emerge as an agent that attempts to resolve the complication that surfaces. Notwithstanding such action towards an event depends a lot on the individual's perception of the situation at hand. Each individual will respond or react to the stressful situation, according to their capacity (Coyle et al., 2000).

This study found that religious coping was the common mediator in all five components of illness perception including time line, illness coherence, personal control, consequences of disease and cycle with the quality of life for mental and physical components. Religious coping played a significant role in influencing the HRQoL of the ESRD population studied. Several other researchers have also found that there are many individuals who have not been religious or whose religious practices slackened. However, in the face of major stressful situations they will eventually return to their religions to enable them to feel more comfortable and secure (Koenig, 2001; Koenig et al., 2001). This usually involves renewed faith and belief in life and God, being involved in religious activities, reading books based on religion in order to obtain guidance, motivation or support among pious members of the religion to help them cope. There are many studies which found religion to be a powerful source 
of hope, meaning in life, peace of mind. These findings are particularly evident in individuals who are sick and disable (King, 2000; Koenig et al., 1998; Koenig, 2004; Mueller et al., 2001) or facing end of life dilemmas.

ESRD patients also face a somewhat, similar end of life dilemma resolved only by dialysis with its stringent dictates and expenses. The patients in this study utilized the positive form of religious coping. Praying and performing prayers or solat (for Muslims) are ways of being close to God. Involvement with religious activities and their pious peers increase their confidence with God's mercy and assistance. Most of the patients also had their solid religious background and makes them more accepting of 'God's trials' and to turn to religion under adverse circumstances. This may explain the impact of religious coping which served as the mediator between the five components of illness perception with HRQoL.

Apart from that, according to Heijmans (1998) and Helder et al. (2002) coping strategies had become the mediator between illness perception and outcome. Gray and Rutter (2007) also reported that coping strategies to be partial mediators in the relationship between several components of illness perception with quality of life. However, the coping strategies employed by the subjects of their study were somewhat different from those employed in the current study. Although the role of religious coping was substantial in this research subjects, such that it had become the mediator to several components of the illness perception with HRQoL, the adoption of other coping strategies must also be taken into account since human beings do not resort to only one form of strategy in handling problems. For instance, Yeh and Chau (2007) demonstrated that their HD patients employed various forms of coping strategies. However, the problem-oriented coping strategy is frequently used by the majority of dialysis patients to overcome their stressors, as addressed by Baldree et al. (1982), and Gulkis and Menke (1995). Thus there are differences among individuals in different geographical location dealing with their problems and the coping strategies used are also different and multiple.

\section{Conclusion}

In conclusion, this study show the importance of religious coping strategies and its impact on illness perception and HRQoL of Malaysian patients with ESRD on chronic dialysis. These findings should be given due attention in any interventional program to improve the HRQoL of patients.

\section{References}

Baldree, K., Murphy, S., \& Powers, M. (1982). Stress, identification and coping patterns in patients on haemodialysis. Nursing Research, 37(2), 107-112.

Cameron, L. D., \& Moss-Morris, R. (2004). Illness-related cognition and behavior. In Kaptein, A. D. \& Weinman, J. (Eds.), Health Psychology (pp. 84-110). Blackwell: Australia.

Coyle, D., Edwards, D., Hannigan, B., Burnard, P., \& Fothergill, A. (2000). An explanation of the coping strategies used by community psychiatric nurses in Wales. Nursing and Health Sciences, 2(1), 59-67. http://dx.doi.org/10.1046/j.1442-2018.2000.00040.x

Finkelstein, F. O., West, W., Gobin, J., Finkelstein, S. H., \& Wuerth, D. (2007). Spirituality, quality of life and the dialysis patients. Nephrology Dialysis Transplantation, 22(9), 2432-2434. http://dx.doi.org/10.1093/ndt/gfm215

Fowler, C., \& Baas, L. S. (2006). Illness representations in patients with chronic kidney disease on maintainance Hemodialysis. Nephrology Nursing Journal, 33(2), 173-187.

Gall, T. L., \& Grant, K. (2005). Spiritual disposition and understanding illness. Pastoral Psychology, 53(6), 515-533. http://dx.doi.org/10.1007/s11089-005-4818-y

Gray, S. E., \& Rutter, D. R. (2007). Illness representations in young people with chronic fatigue syndrome. Psychology and Health, 22(2), 159-174. http://dx.doi.org/10.1080/14768320600774595

Gulkis, J. A., \& Menke, E. M. (1995). Chronic hemodialysis patients perceptions of stress, coping and social support. Anna Journal, 2(4), 381-390.

Hagger, M., \& Orbell, S. (2005). A confirmatory factor analysis of the revised illness perception questionnaire (IPQ-R) in cervical screening context. Psychology and Health, 20(20), 161-173. http://dx.doi.org/10.1080/0887044042000334724

Heijmans, M. (1998). Coping and adaptive outcome in chronic fatigue syndrome: Importance of illness $\begin{array}{llll}\text { cognitions. Journal of Psychosomatic Research, } & \text { 45(1), }\end{array}$ http://dx.doi.org/10.1016/S0022-3999(97)00265-1 
Helder, D. I., Kaptein, A. A., van Kempen, G. M. J., Weinman, J., van Houwelingen, H. C., \& Roos, R.A.C. (2002). Living with Huntington's disease: Illness perceptions, coping mechanisms, and patients' well-being. British Journal of Health Psychology, 7(4), 449-462. http://dx.doi.org/10.1348/135910702320645417

Kimmel, P. L., Emont, S. L., Newman J. M., Danko, H., \& Moss, A. H. (2003). ESRD patient quality of life: Symptoms, spiritual beliefs, psychosocial factors, and Ethnicity. American Journal of Kidney Disease, 4(4), 713-721. http://dx.doi.org/10.1016/S0272-6386(03)00907-7

King, D. E. (2000). Faith, spirituality and medicine: Toward the making of the healing practitioner. Binghamton, NY: Haowth Press.

Ko, B., Khurana, A., Spencer, J., Scott, B., Hahn, M., \& Hammes, M. (2007). Religious beliefs and quality of life in an American inner-city haemodialysis population. Nephrology Dialysis Transplantation, 22(10), 2985-2990. http://dx.doi.org/10.1093/ndt/gfm341

Koenig, H. G. (2001). Religion and medicine II: Religion, mental health, and related behaviors. International Journal of Psychiatry in Medicine, 31(1), 97-109. http://dx.doi.org/10.2190/BK1B-18TR-X1NN-36GG

Koenig, H. G. (2004). Religion, spirituality, and medicine: Research findings and implications for clinical practice. South Medical Journal, 97(12), 1194-1200.

Koenig, H. G., McCullough, M. E., \& Larson, D. B. (2001). Handbook of religion and health. New York: Oxford University Press.

Koenig, H. G., Pargament, K. I., \& Nielsen, J. (1998). Religious coping and health status in medically ill hospitalized older adults. Journal of Nervous \& Mental Disease, 186(9), 513-521.

Malaysian Dialysis, \& Transplant Registry. (2009). 17th Report of the Malaysian Dialysis and Transplant Registry 2009. National Renal Registry Malaysian Society of Nephrology. Kuala Lumpur.

Mapes, D. L., Lopes A. A., Satayathum, S., Mccullough, K. P., Goodkin, D. A., Locatelli, F., Fukuhara, S., ... Port, F. K. (2003). Health-related quality of life as a predictor of mortality and hospitalization: The Dialysis Outcomes and Practice Patterns Study (DOPPS). Kidney International, 64(1), 339-349. http://dx.doi.org/10.1046/j.1523-1755.2003.00072.x

Mattison, D. (2006). The forgotten spirit: Integration of spirituality in health care. Nephrology News and Issues, 20(2), 30-32.

Mok, E., \& Tam, B. (2001). Stressors and coping methods among chronic hemodialysis patients in Hong Kong. Journal of Clinical Nursing, 10(4), 503-511. http://dx.doi.org/10.1046/j.1365-2702.2001.00493.x

Moss-Morris, R., Weinman, J., Petrie, K. J., Horne, R., Cameron, L., \& Buick, D. (2002). The revised illness perception questionnaire (IPQ-R). Psychology and Health, 17(1), 1-16. http://dx.doi.org/10.1080/08870440290001494

Mueller, P. S., Plevak, D. J., \& Rummans, T. A. (2001). Religious involvement, spirituality, and medicine: Implications for clinical practice. Mayo Clinic Proceedings, 76(12), 1225-1235. http://dx.doi.org/10.1016/S0025-6196(11)62799-7

Norhayati Ibrahim, Asmawati Desa, Norella Kong Chiew Thong, R. Ismail, \& A. Z. Zainah. (2011). Social support and religious coping strategies in health-related quality of life of end-stage renal disease patients. Pertanika Journal of Social Sciences \& Humanities, 19(S), 91-98.

Norhayati Ibrahim, Norella Kong, \& Asmawati Desa. (2011). Illness perception and health-related quality of life among haemodialysis patients. Pertanika Journal of Social Sciences \& Humanities, 19(S), 173-181.

Patel, S. S., Shah, V. S., Peterson, R. A., \& Kimmel, P. L. (2002). Psychosocial variables, quality of life and religious belief in ESRD patients treated with haemodialysis. American Journal of Kidney Disease, 40(5), 1013-1022. http://dx.doi.org/10.1053/ajkd.2002.36336

Reynolds, N., \& Alonzo, A. A. (2000). Self-regulation: The common-sense model of illness representation. In V.H.Rice (Ed.), Handbook of stress, coping and health (pp. 483-494). Thousand Oaks, CA: Sage.

Timmers, L., Thong, M., Dekker, F. D., Boeschotten, E. W., Heijmans, M., Rijken. M., \& Weinman, J. (2008). Illness perceptions in dialysis patients and their association with quality of life. Psychology \& Health, 23(6), 679-690. http://dx.doi.org/10.1080/14768320701246535 
Tix, A. P., \& Frazier, P. A. (1998). The use of religious coping during stressful life events: Main effects, moderation, and mediation. Journal of Consulting Clinical Psychology, 66(2), 411-422. http://dx.doi.org/10.1037/0022-006X.66.2.411

Tsay, S. L., Lee, Y. C., \& Lee, Y. C. (2005). Effects of an adaptation traning programe for patients with end-stage renal disease. Journal Advance Nursing, 50(1), 39-46. http://dx.doi.org/10.1111/j.1365-2648.2004.03347.x

Ware, J. E., Snow, K. K., Kosinski, M., \& Gandek, B. (1993). SF-36 Health survey. Manual and Interpretation Guide. Boston: Nimrod Press.

Yeh, S-C.J., \& Chau, H-C. (2007). Coping strategies and stressors in patients with hemodialysis. Psychosomatic Medicine, 69, 182-190. http://dx.doi.org/10.1097/PSY.0b013e318031cdcc 